\title{
Pity the poor gatekeeper: a transatlantic perspective on cost containment in clinical practice
}

\author{
Thomas R Taylor
}

The inevitable effects of demographic changes and the escalating expectations raised by high technology medicine are that health costs are rising all over the developed world. The issues being debated in relation to the white paper Working with Patients are the same ones facing the Canadian and American health care systems. ${ }^{1-4}$ Limits have to be set on health care expenditure. But setting limits means setting priorities and making choices. This is not new: renal dialysis units have faced such limits for decades, and doctors differ widely in the factors they take into account in selecting patients for dialysis.

Most of the discussion in the $B M \mathcal{F}$ has focused on policy, political, and administrative issues..$^{6-8}$ Although undesirable effects on the doctor-patient relationship have been predicted in discussions on the white paper, they have not been studied systematically. As part of the ongoing debate on practice budgets and cost restraint I recorded the experiences of primary care doctors who had acted as gatekeepers in a large health maintenance organisation.

\section{Role of health maintenance organisations in cost containment}

In the United States the need for cost containment has been recognised for some years, and several different organisational and managerial approaches have been used. Among the most important of these is the setting up of health maintenance organisations..$^{9 \cdot 10}$ Though the long term contribution of health maintenance organisations to cost containment is controversial, this remains an important approach that continues to be popular with purchasers of health care in the United States. Reece analysed the problems and shortcomings of managed health care from the doctor's perspective based on experience with corporate medicine in Minnesota. ${ }^{11}$ This state has been a pioneer in this approach to cost containment.

The role of the primary care doctor in the health maintenance organisation is to act as case manager or gatekeeper. The organisation identifies as gatekeeper a primary care provider who has responsibility for primary care, for coordinating care by referral specialists, for authorising hospital admissions, and for coordinating emergency care. Practices participating in the organisation receive monthly capitation payments for outpatient medical services, and an additional monthly amount is placed in a shared risk pool for hospital admissions, extended care, mental health care, prescriptions, and inpatient related professional fees. There are strong financial incentives to use a limited panel of specialists who provide consultation at discounted rates. Surpluses remaining at the end of the year are returned to the practice, creating incentives for cost containment.

The cost of membership of a health maintenance organisation in the United States is usually provided by employers, with a choice among several competing organisations, schemes being provided to employees on a yearly or half yearly renewable basis as part of their benefits package. The parallel between the gatekeeper role and a practice with cash limits arises when the practice limits are in danger of being exceeded (for example, late in the financial year) and appreciable cost savings must be achieved. This paper summarises the key findings of a study of 48 doctors who had been performing the gatekeeper role for at least three years in the HealthPlus health maintenance organisation in Seattle, Washington.

\section{Methods}

The data used in this study were derived as follows:

- From individual interviews of 40 family doctors: of the 40 participants, 18 were in academic practice and 22 were in community practice. Those in community practice were independently selected by the medical directors in the clinics in which they practised to represent a range of experience and opinions about the gatekeeper role. The likeliest direction of bias in selection would have been towards those favourably disposed towards the concept of health maintenance organisation.

- From focus group interviews of 24 doctors (in groups of up to five) from both academic and community practices. The focus group interview technique is a qualitative approach to learning about opinion subgroups within a population. It tries to get at the reasons behind opinions that are identified in surveys. ${ }^{12}$ The transcripts of both the interviews and the focus group discussions were analysed by the techniques of content analysis. ${ }^{13}$

- By reviewing the case records of all health maintenance organisation patients in the practice panel of four individual doctors. The review technique entailed assembling all the patients' charts in each doctor's panel of patients. The doctor then reviewed each chart with an interviewer to recall any gatekeeper decisions made on that patient. The decisions yielded by this technique were broadly similar to those arising in the focus groups. The panel review yielded 22 gatekeeping decisions. Overall, about $15 \%$ of the charts showed a gatekeeping decision; there was never more than one decision recalled in any single chart. This approach, however, records only overt conflict that was recorded in the chart and takes no account of less pronounced conflict or the efficacy of the methods of coping described below. It tends, however, to confirm the subjective observation of many doctors that the problems that arise with the gatekeeping role are not confined to the difficult patients in the practice but affect a wide range of patients. The remaining 21 decisions arose in the focus group interviews.

The data yielded by these techniques were of two 


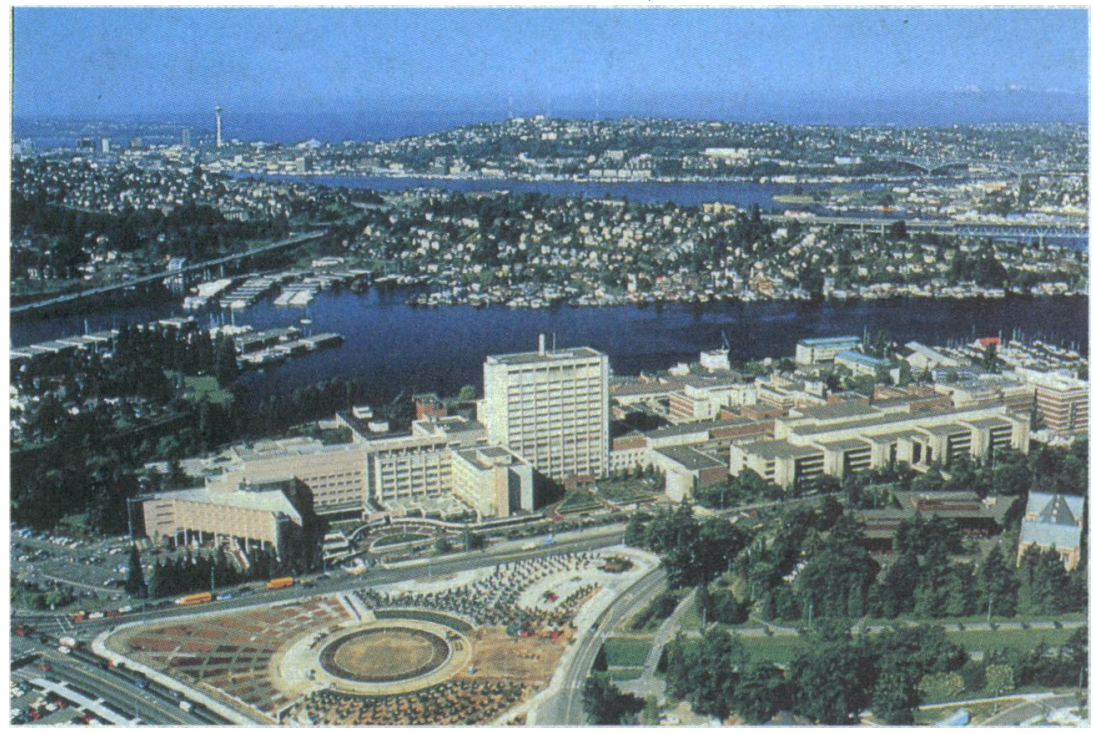

University of Washington Medical Center

types: firstly, a series of decisions or clinical problems $(n=43)$ that the doctors either individually or in the focus groups believed exemplified the gatekeeper role and, secondly, statements from the doctors about their perceptions of the role and how they cope with it. The gatekeeper decisions were identified as such by the doctors themselves. All of the decisions cited entailed overt conflict between patient and doctor. Overt conflict was defined as doctor and patient verbally disagreeing with one another about a gatekeeper decision and this being recorded in the patient's chart or recalled in the focus group. The doctors in this study acknowledged that many other gatekeeping decisions were taken covertly (to limit access to care) without the patient being aware of the influence of costs on the choice of care provided to them. More detailed analysis of the above data will be the subject of future publications.

\section{Results}

This report highlights some of the findings and conclusions that seem to be relevant to the current and projected problems concerned with cost containment in the NHS. No differences in findings were apparent between academic and community based doctors. As far as I know no other studies on gatekeeping have approached the problem of defining the role and its problems by focusing on decisions and methods of coping.

\section{GATEKEEPING DECISIONS}

The decisions yielded by focus group discussions and the practice panel review $(n=43)$ were of the following types.

- Those focused on limitations to investigation and treatment $(15 / 43)$

(1) The patient insists on diagnostic tests considered unnecessary by family doctors - for example, radiography for hand or knee pain, upper gastrointestinal series for stomach pain, and skin testing for allergies

(2) The doctor chooses a less expensive and somewhat less effective treatment, causing conflict with the patient - for example, giving nicotinic acid rather than more expensive cholesterol lowering drugs, or refusing to authorise the use of biofeedback for migraine

- Those entailing conflict about the referral process (18/43).

(1) The patient requests referral to a specialty clinic, such as an ear, nose, and throat clinic; a back pain clinic; or physiotherapy; often the condition is a self diagnosed condition and the family doctor believes that the problem can and should be handled at their level

(2) The patient asks for referral to a specialist. The family doctor agrees, but the specialist has an excess of authorised visits or procedures, or both, and refers the patient to yet another specialist without authorisation from the family doctor

(3) Either the patient or the family doctor think that a referral is appropriate. The plan, however, does not generally cover the service. Among the commonest are infertility, psychotherapy ( $>10$ sessions), and certain preventive services (such as mammograms). The doctor then spends hours making telephone calls negotiating an exception

(4) The doctor decides referral is appropriate. The patient is seen by a member of the health maintenance organisation's "in house" panel of specialists who think that the patient's condition is beyond their expertise. An outside specialist is recommended. The organisation's medical director wants treatment done in house, but the in house specialist refuses.

Apart from these two main groups of problems other gatekeeping decisions impinged less commonly on other aspects of the doctor-patient relationship. These types of decisions included the following.

- A dysfunctional doctor-patient relationship (2/43).

A dysfunctional relationship is played out by the patient demanding more tests or referrals and interpreting the denial of such access as a refusal by the doctor to attend to their needs

- Ethical issues (4/43).

Patients put pressure on the doctor to misrepresent the nature of their problems so as to get around the limitations dictated by costs. Such issues take a long time to resolve. Some doctors, because of their inability or unwillingness to resist such pressures, place an extra burden on other members of the practice to hold costs down to compensate for such breaches of policy

- Decisions involving continuity of care (4/43).

Family doctors may deny the need for a certain test because it is not clinically justifiable. The patient is insistent. The doctor leaves on vacation. The patient makes an appointment with another provider in the same clinic. This provider authorises the test (for example, computed tomography).

\section{Methods of coping with gatekeeping conflicts}

The doctors were asked how they coped with the conflicts associated with making these difficult decisions. The commonest methods of coping described were as follows.

- Placing a strong (but time consuming) emphasis on educating the patient when they are admitted to the plan, with particular emphasis on the limitations-for example "we do not do skin testing for allergies" or "we do not pay for infertility workups"

- Playing for time on a problem. This is probably the most widely used and effective tactic as patients may lose interest in following up a problem or having investigations done

- When overt conflict about denying patients access to investigations or treatment arises doctors will (by their own admission) shift the blame to third parties, "It's not my fault" or adopt a false advocacy role, "I will try and get a good deal for you with the medical director of the plan"

- Letting the plan pay; taking the path of least resistance; and ignoring the problem. This has the effect of putting more pressure on colleagues to hold the line on costs 
- Getting round the rules: being a genuine advocate within the plan of having exceptions made; this is very time consuming.

\section{EFFECT ON THE DOCTOR-PATIENT RELATIONSHIP}

Doctors during interviews and in the course of focus group sessions expressed several opinions on how the gatekeeper role has affected their relationship with their patients. Their beliefs were as follows.

- It has compromised their role as patient advocate

- There has been a loss of trust owing to perceived financial conflict of interest

- There are financial incentives to breech the principles of informed consent. This is done (to avoid conflict) by withholding information about plan provisions or not admitting that some cost saving choices entail a diminution in efficacy

- A negative tone is imposed on the relationship by the need to emphasise the unfavourable aspects of the plan

- Doctors feel an unavoidable pressure to make a trade off between medical benefit to the patient and financial risk to the doctor

- The doctor's credibility is undermined by granting exceptions to the plan so as to avoid conflict.

\section{Discussion}

Though it is difficult to generalise from the limited sample of doctors in this study, the types and levels of conflict that they reported are broadly similar to those described in other studies. ${ }^{14-18}$ The problem of generalisability is difficult to assess in studies such as this. I measured only overt conflict and clearly underrepresented the impact of any other conflicts on the doctor-patient relationship. There have been no suggestions (the above data has been presented to large groups of doctors at continuing medical education courses) that these findings are biased or anomalous. The sources of the conflict in all these studies seem to fall under two broad headings: firstly, loss of autonomy of the doctor with the threat of losing professionalism, and secondly, the long and short term implications of limiting access to investigations and treatment.

The perspective in all of these studies is that though it is possible to view the role positively, the overwhelming impression is of conflict, alienation, and apprehension on the part of doctors. Clearly, health care costs must be contained, and conflict is inevitable when patients have always been used to regarding health care as "free" and without limits.
On the basis of this and other studies it can be concluded that practice budgets, if implemented, will appreciably increase overt and covert conflict among doctors (both specialists and general practitioners) and between doctors and patients. If cost containment is to yield financially important savings it will be time consuming and entail reappraisal of well established strategies concerning referrals and acceptable levels of investigative workup. The same process will have appreciable impact on the doctor-patient relationship. The process of deferring or omitting investigations and treatments will, as in the United States, expose doctors to a greatly increased risk of malpractice even in the very different malpractice climate in the United Kingdom. As patient discontent with the quality of service increases and lawyers look for new ways to fill the gap left by loss of conveyancing and probate business contingency fees cannot be far behind.

I thank Professor D J G Bain and Dr Kevin Jones of the department of primary medical care, University of Southampton for their help in reviewing this manuscript. The study was funded by the Family Health Foundation of America, Missouri.

1 Enthoven AC. Reflections on the management of the national health services. London: Nuffield Provincial Hospital Trust, 1985.

Enthoven A, Kronick R. A consumer-choice health plan for the 1990's. N Engl 7. Med 1989;320:94-101.

Himmelstein DU, Woolhandler SA. National health program for the United States. N Engl f Med 1989;320:102-7.

4 Evans GE, Lomas J, Baker ML, et al. Controlling health expenditures-the Canadian reality. $N$ Engl f Med 1989;320:571-7.

5 Taylor TR, Aitchison J, Parker I, Moore M. Individual differences in selected patients for regular haemodialysis. Br Med f 1975;ii:380-1.

6 Robinson R. New health care market. Br Med f 1989;298:437-9.

7 Leavev R, Wilkin D, Metcalfe DHH. Consumerism and general practice. Br.Med f 1989;298:737-9.

8 Harris A. A GP's perspective. Br Med f 1989;298:884-5.

9 Geyman JP. Family practice and the gatekeeper role. I Fam Pract 1983;17: $587-8$

10 Eisenberg JM, Williams SU. Cost containment and changing physicians' practice behavior: Can the fox learn to guard the chicken coop? $7 A M A$ 1981;246:2195-201

11 Reece RL. The corporate transformation of medicine in Minnesota: the grande finale and the grande finesse. Minn Med 1987;70:609-13.

2 Basch CE. Focus group interview: an underutilized research technique for mproving theory and practice in health education. Health Educ $Q 1987 ; 14$ mproving

3 Holsti OR. Content analysis for the social sciences and humanities. Reading: Addision Wesley Publishing Company, 1969

14 Ellsbury $\mathrm{K}$. Gatekeeping-clinical and administrative issues. West $\mathcal{f}$ Med 1986:145:254-7.

15 Reagan MD. Physicians as gatekeepers. N Engl f Med 1987;317:1731-4.

16 Somers AR. And who shall be gatekeeper? The role of the primary care physician in the health care delivery system. Inquiry 1984;20:301-13

17 Somers AR, Somers HM. A proposed framework for health and health care policies. Inquiry 1977; 14:115-70

18 Ellsbury KRE, Montano DE, Manders D. Primary care physicians' attitudes about gatekeeping. $f$ Fam Pract 1985;25:616-9.

Accepted 27 September 1989

\section{MATERIA PARAMEDICA}

\section{Dropping in}

Intravenous drip infusions ${ }^{1}$ have been used for more than 300 years. J B S Haldane noted that Sir Christopher Wren invented the intravenous injection of drugs and blood transfusion in 1659. His success on dogs, wrote Pepys in his diary, "did give occasion to many pretty wishes, as of the blood of a Quaker to be let into an Archbishop, and such like; but may, if it takes, be of mighty use to man's health, for the amending of bad blood by borrowing from a better body.":

Infusion of normal saline solution was described by Walter Brown in 1889. ${ }^{3}$ Brown's patient was a lady who had vomited continuously for some hours. He used Aveling's transfusion apparatus to inject 25 ounces of normal saline solution, with the result that "in a few minutes she rallied, the pulse became perceptible and her aspect improved." Brown later wrote on "Continuous transfusion as a means of preventing shock in prolonged operations." ${ }^{\prime} \mathrm{He}$ was honorary surgeon at Leeds General Infirmary, and one of his patients was Thomas Dobson, an elderly retired general practitioner in Leeds, whose niece was the mother of Will Pickles, later a distinguished practitioner in Wensleydale. Dr Dobson had a strangulated hernia and he had a haemorrhage a few days after Brown had operated on him. A Dr Woodcock “sped to 'Gaffer' Brown's house . . . but no response was given to his urgent ringing of the bell. He left and contacted the young Moynihan (later Lord Moynihan, PRCS) who fetched out his own bicycle and went with Dr Woodcock to Holbeck, where he dealt with the haemorrhage. Brown was much upset and explained that he had never heard the bell. He was a great entertainer and that night he had had Conan Doyle staying with him." Walter Brown died in 1907, aged 50.- LESLIE TURNER

1 Freedman BJ. A ray of sunshine for old ladies: a tip for the geriatricians? Br Med $\mathcal{f}$ 1989;299:441 2 Haldane JBS. Possible worlds and other essays. London: Chatto and Windus, 1930:86.

3 Brown W'H. Case of transfusion of the normal saline solution. Lancet 1889;i:527.

4 Anonvmous. Brown WH. Obituary notice. Lancet 1907;ii:673.

5 Pemberton J. W'ill Pickles of W'enslevdale. Newton Abbot: Country Book Club, 1972:25-6. 